\title{
LOS INVENTARIOS, HAMILTON Y EL PREMIO DE LA PLATA
}

\author{
JESUS AGUADO DE LOS REYES \\ Universidad de Sevilla
}

Con motivo de la elaboración de mi tesis doctoral ${ }^{1}$, me vi obligado, dada la época que la misma abarca - primera mitad del siglo XVII- a aplicar, bastante a menudo, el premio de la plata a las valoraciones de bienes reflejadas en moneda de vellón en los inventarios.

La documentación no siempre precisa el premio vigente en los momentos del aprecio. Por ello, en ausencia de este dato, hube de recurrir a una fuente complementaria para salvar los problemas de bimetalismo y consideré oportuno utilizar, con este motivo, las tablas elaboradas por Hamilton en dos de sus obras capitales ${ }^{2}$, corroborando, a través del trabajo, la coincidencia entre las mencionadas tablas de Hamilton y los premios señalados en la documentación notarial, como puede comprobarse en el cuadro y la gráfica adjunta.

Todo ello viene a certificar la validez del trabajo realizado por el eminente historiador.

Como puede apreciarse, las diferencias entre ambas series, en lineas generales, son poco abultadas. En los casos o años más llamativos, el distanciamiento obedece a la concentración de inventarios en una determinada época del mismo, distinta a las subidas reflejadas por Hamilton. Al realizar éste un cómputo basado en medias cuatrimestrales, las variaciones bruscas, a veces, no coinciden con las fechas de los inventarios, que señalan siempre el premio vigente en el momento de su realización. De ahí, esas pocas disparidades observadas entre ambas series.

1 Aguado de los Reyes, Jesús (1992).

2 Hamilton (1975), p. 108, y (1988), p. 58. 


\begin{tabular}{|c|c|c|c|}
\hline & Años & Premio aplicado & Hamilton \\
\hline 1620 & 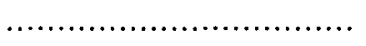 & 4,00 & 4,00 \\
\hline 1621 & $\ldots \ldots \ldots \ldots \ldots \ldots \ldots \ldots \ldots \ldots \ldots$ & 4,00 & 4,00 \\
\hline 1622 & 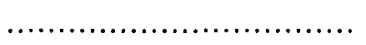 & 5,88 & 5,48 \\
\hline 1623 & 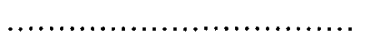 & 8,33 & 9,73 \\
\hline 1624 & $\ldots \ldots \ldots \ldots \ldots \ldots \ldots \ldots \ldots \ldots \ldots, \ldots$ & 11,43 & 11,45 \\
\hline 1625 & …........................... & 11,20 & 12,25 \\
\hline 1626 & 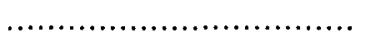 & 29,43 & 40,94 \\
\hline 1627 & 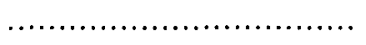 & 37,68 & 37,10 \\
\hline 1628 & 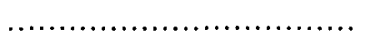 & 29,43 & 36,56 \\
\hline 1629 & 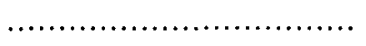 & 16,69 & 16,81 \\
\hline 1630 & 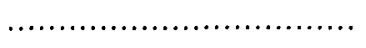 & 21,40 & 21,15 \\
\hline 1631 & 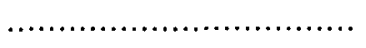 & 20,25 & 19,25 \\
\hline 1632 & 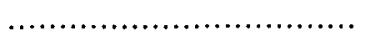 & 17,67 & 18,50 \\
\hline 1633 & 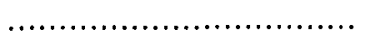 & 20,79 & 22,91 \\
\hline 1634 & 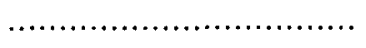 & 25,75 & 27,38 \\
\hline 1635 & 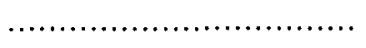 & 24,96 & 25,31 \\
\hline 1636 & 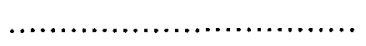 & 24,91 & 25,15 \\
\hline 1637 & 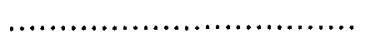 & 27,61 & 29,39 \\
\hline 1638 & 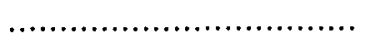 & 35,00 & 35,75 \\
\hline 1639 & 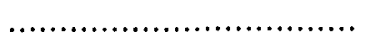 & 25,33 & 31,90 \\
\hline 1640 & 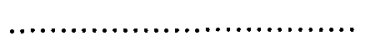 & 43,83 & 48,00 \\
\hline 1641 & 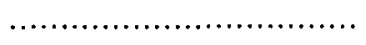 & 46,06 & 62,69 \\
\hline 1642 & 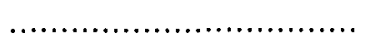 & 75,53 & 120,62 \\
\hline 1643 & 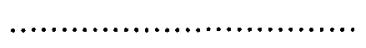 & 29,31 & 32,92 \\
\hline 1644 & 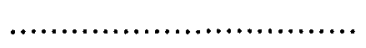 & 30,39 & 32,29 \\
\hline 1645 & 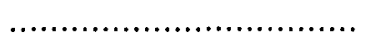 & 32,85 & 35,81 \\
\hline 1646 & 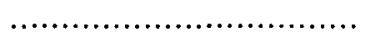 & 41,86 & 41,18 \\
\hline 1647 & 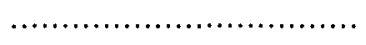 & 36,42 & 39,48 \\
\hline 1648 & (n.w. & 40,55 & 41,04 \\
\hline 1649 & (n) & 41,20 & 43,32 \\
\hline 1650 & (n) & 46,63 & 50,06 \\
\hline 1651 & 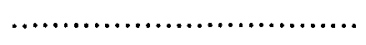 & 48,38 & 53,00 \\
\hline 1652 & (.). & 50,00 & 50,25 \\
\hline 1653 & 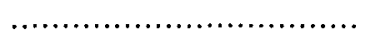 & 50,00 & 50,00 \\
\hline 1654 & & 45,38 & 50,50 \\
\hline 1655 & 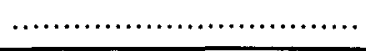 & 50,00 & 50,00 \\
\hline
\end{tabular}




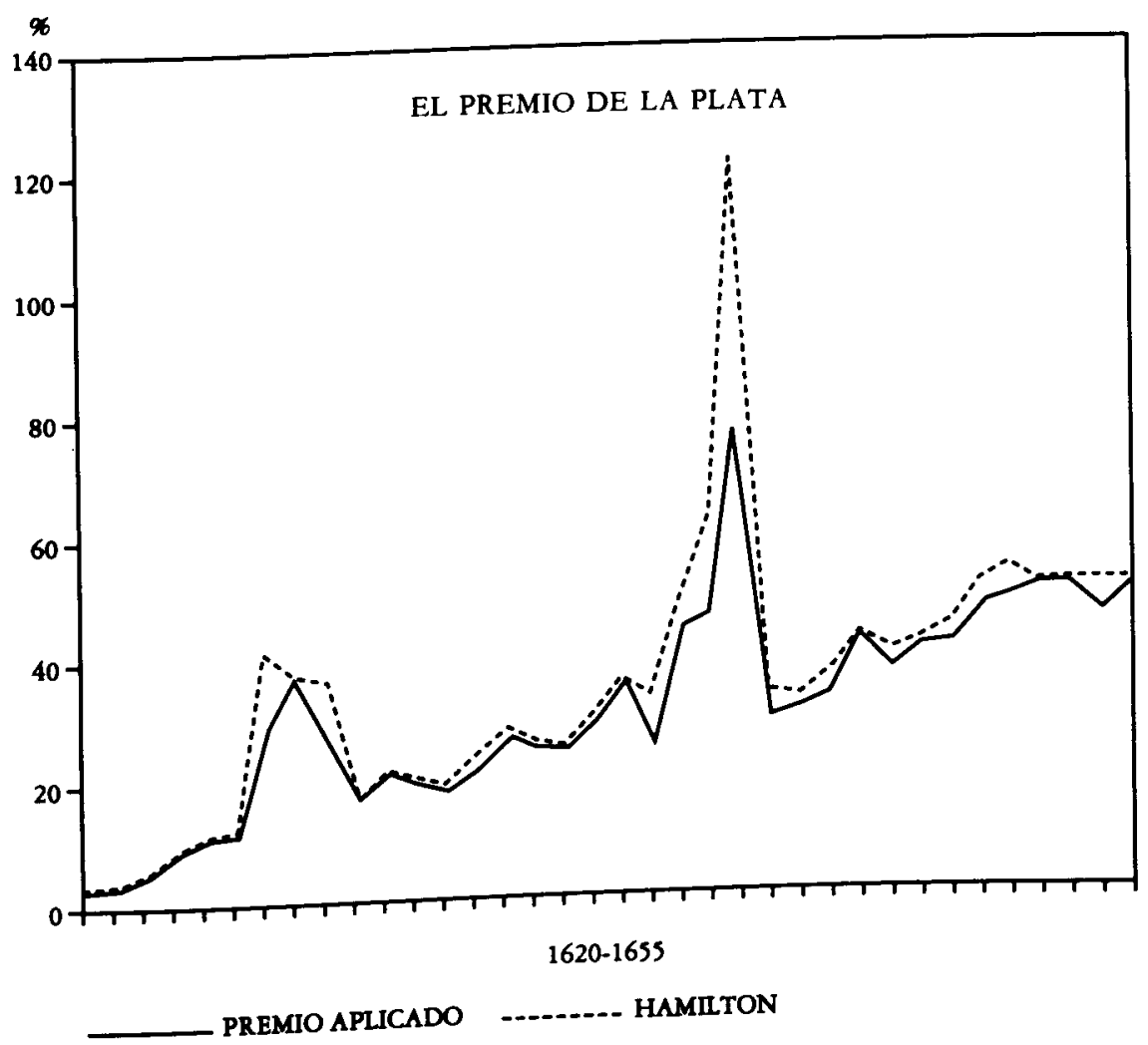

\section{REFERENCIAS}

AGUADO DE LOS REYES, J. (1992): Los inventarios de bienes post-mortem en la Sevilla del Siglo XVII (1600-1655), Tesis doctoral presentada en la Universidad de Sevilla. HAMILTON, E. J. (1975): El tesoro americano y la revolución de los precios. 1501-1650, Barcelona, Ariel.

(1988): Guerra y precios en España. 1651-1800, Madrid, Alianza, p. 58. 